\title{
A Latent Profile Analysis of Problematic Media Device Use and Its Association With Executive Function and Behavioral Problem Among Children: A Population-Based Study
}

\author{
Yunhye Oh${ }^{1}$, Youngmi Kim², and Yoo-Sook Joung ${ }^{3 凶}$ \\ ${ }^{1}$ Department of Child and Adolescent Psychiatry, National Center for Mental Health, Seoul, Republic of Korea \\ ${ }^{2}$ Department of Child Welfare and Counseling, Gukje Cyber University, Suwon, Republic of Korea \\ ${ }^{3}$ Department of Psychiatry, Samsung Medical Center, Sungkyunkwan University School of Medicine, Seoul, Republic of Korea
}

Objective Despite the rapid increase in problematic media device use, relatively little is known about specific characteristics and extent of problematic media device and how they relate to different psychological features.

Methods Data extracted from the Panel Korea Study for the Child Cohort Study were used. At the age of 9 years, media device addiction severity was assessed using the K-scale, and children's behavioral outcomes were assessed using the Child Behavior Checklist. Among children with problematic media device use $(n=339)$, we performed latent profile analysis using the K-scale to identify subtypes of problematic media device use, and then compared the child behavioral problems and executive function according to the different subtypes of problematic media device use.

Results Children with problematic media device use were divided into class $1(n=51)$, class $2(n=138)$, and class 3 ( $n=150)$. Compared with classes 2 and 3, class 1 had more severe problematic media device use, including daily activity disturbance, withdrawal, and tolerance. Class 1 had the most serious behavioral problems and executive function difficulties among classes. Class 2 had greater daily activity disturbance and tolerance than those of class 3, but executive function showed no significant difference between the two classes. In logistic regression analysis, behavioral problems except for somatization were more common in class 1 than in the control group.

Conclusion Results suggest that problematic media device use is associated with significant behavioral problem and executive function difficulties and underscore the need for further clinical and research attention for these specific subgroup members.

Psychiatry Investig 2021;18(9):895-903

Keywords Problematic media device use; Child behavior problem; Executive function; Latent profile analysis.

\section{INTRODUCTION}

Due to the rapid growth of information technology and mobile communication, personal computers and smartphones have become very popular among children and adolescents. ${ }^{1}$ The purpose of media use has also been diversified to include information seeking, communication, education, and entertainment, and the use of media devices has become indispensable to children and adolescents. ${ }^{2}$ Despite the various benefits

Received: April 12, 2021 Revised: June 25, 2021

Accepted: July 18, 2021

$\triangle$ Correspondence: Yoo-Sook Joung, MD, PhD

Department of Psychiatry, Samsung Medical Center, Sungkyunkwan University School of Medicine, 81 Irwon-ro, Gangnam-gu, Seoul 06351, Republic of Korea

Tel: +82-2-3410-0930, Fax: +82-2-3410-0052, E-mail: yschoung@skku.edu

(a) This is an Open Access article distributed under the terms of the Creative Commons Attribution Non-Commercial License (https://creativecommons.org/licenses/bync/4.0) which permits unrestricted non-commercial use, distribution, and reproduction in any medium, provided the original work is properly cited. of using media devices, their excessive use has become a growing concern in modern society.

Researchers have demonstrated that excessive media device use has a negative influence on children's physical and psychological health and academic achievement..$^{5-7}$ Previous studies on children and adolescents demonstrating negative concerns about media device use have focused on psychopathology and found that impulsivity, inattention, hyperactivity, anxiety, and depression are positively related to media device addiction..$^{8-10}$ However, little is known about problematic media device use in younger children, but not in older children.

Internet gaming disorder (IGD) is registered as a research category in DSM 5 and has received considerable clinical attention. ${ }^{11}$ IGD has been reported to be associated with aggressive behavior, impulsivity, sleep problem, anxiety, inattention, and hyperactivity. ${ }^{12,13}$ Similarly, it has been reported that the problematic behavior similar to that in IGD is observed in Internet 
and smartphone addiction. ${ }^{14,15}$ However, since the Internet and smartphones are used for various purposes, it is difficult to conclude that excessive internet/smartphone use causes the same outcomes. Media device usage patterns are heterogeneous; therefore, it is difficult to specify certain patterns and define pathological use. Thus, in order to determine the definition and extent of media device addiction and identify related problematic behaviors, further study considering the heterogeneity of excessive media device use is necessary.

Latent profile analysis (LPA) is a statistical approach used to identify subtypes of problematic media device use. ${ }^{16}$ Rather than the classical statistical method, LPA may be a helpful method for revealing latent and homogeneous populations and profiles of meaningful groups. ${ }^{17}$ LPA has been applied in previous studies to find appropriate classifications of IGD, smartphone addiction, and Internet addiction. ${ }^{18,19}$ But, most previous studies were classified based on the purpose of media device use (education, entertainment, information seeking) or the type of device (smartphone, personal computer, television), or classified according to the quantitative use time..$^{20-22}$ In addition, the subjects of previous studies were limited to adolescent and adult populations. ${ }^{19,22}$ However, since media device addiction is based on core symptoms characteristic of behavioral addiction rather than the quantitative aspect of media device use, it is more appropriate to classify it according to symptoms of media device addiction severity. In particular, it is necessary to determine whether these behavioral addiction patterns are also present in children with problematic media device use.

Therefore, this study aimed to identify the subtypes of children with problematic media device use and compare behavioral problems and executive function according to the identified subtypes.

\section{METHODS}

\section{Participants}

This study used data from the 10th year of the Panel Study on Korean Children (PSKC), an annual follow-up survey of 2,150 newborn babies born in 2008. The detailed methodology of the PSKC study has been described elsewhere. ${ }^{23}$ To represent Korean newborn infants in 2008, the PSKC sample was recruited through stratified multi-stage sampling based on the 2008 resident registration population data. The study protocol was approved by the Institutional Review Board of the National Center for Mental Health (IRB No. 116271-2020-41).

We had complete data on media device addiction severity, behavioral problems, and executive function as evaluated in 9-year-old children using the Korean internet addiction scale, Child Behavior Checklist (CBCL 6-18), and executive function difficulty questionnaire scale (EFDSC). The 1,484 house- holds that participated in the 10th year survey conducted in 2017 showed a panel retention rate of $69 \%$ among the original 2,150 households. In this study, the Internet addiction risk group consisted of 339 elementary school 3rd grade children with a media device addiction score of $\geq 28$, comprising 211 boys (62.24\%) and 128 girls (37.76\%).

\section{Measures}

\section{Korea Internet Addiction Scale}

Children's addiction severity to media devices was measured using the K-scale (Korea Internet Addiction Scale) provided by the Korea Information Society Agency as a modified tool in the Korean Children's Panel Study. ${ }^{24,25}$ This scale consists of three factors: daily life disturbance, withdrawal, and tolerance, and was measured according to parental reports. Daily life disturbance measures the degree of difficulty in everyday life, such as school life or interpersonal relations, due to the use of media devices, and consists of a total of five items. Withdrawal measures the degree of irritation or annoyance when a media device is not available and consists of a total of four items. Tolerance consists of a total of four items, measuring the degree to which more stimulating content is added or more immersed in to obtain greater satisfaction. The child's parents responded using a 4-point Likert scale (1=not at all, $4=$ very much so). As a result of the reliability analysis, Cronbach's alpha was 0.885 for elementary school students and 0.899 for middle school students and above. In addition, based on the total score, those with $\geq 30$ points were defined as high-risk users, $28-29$ points as potential risk users, and $\leq 27$ points general users. ${ }^{26}$ Based on the responses, the level of addiction was divided into a general user group (control) and risk group (problematic media device user group, K-scale $\geq 28$ ) according to the specific criteria of the overall score.

\section{Child Behavior Checklist (CBCL 6-18)}

To assess children's problem behaviors, the CBCL 6-18 was used. $^{27}$ The Korean CBCL 6-18 scale, as standardized by Oh et al., ${ }^{28}$ was applied in this study. The Cronbach's alpha for internal consistency for this scale ranged 0.62-0.95. Internalizing problems include anxious/depressed, withdrawn/depressed, and somatization. Externalizing problems include rule-breaking and aggressive behaviors. For each question, the parents of the child responded with a score on a 3-point Likert scale ( $1=$ not at all, $3=$ often), with higher scores reflecting a higher degree of the problem behavior related to each area.

\section{Executive function difficulty screening questionnaire}

Children's executive function was evaluated using the executive function difficulty screening questionnaire developed by 
Song. ${ }^{29}$ This scale was composed of 40 questions, with four factors: 11 items concerning difficulty to plan/organize, 11 items related to difficulty to control behavior, 8 items related to difficulty to control emotions, and 10 items related to inattention. For each question, the caretaker of the child responded using a 3-point Likert scale ( $1=$ not at all, $3=$ often), with higher scores reflecting a higher level of difficulty with respect to executive function. Cronbach's $\alpha$ for each sub-factor was $0.88,0.86,0.92$, and 0.92 , respectively, and the overall reliability was 0.95 .

\section{Statistical analysis}

In this study, a latent profile analysis (LPA) was conducted to identify potential groups according to the level of the child's media device addiction. To determine the optimal model selection, the Akaike information criterion (AIC), Bayesian information criterion (BIC), sample-size adjusted BIC (aBIC), entropy, Vuong-Lo-Mendell-Rubin likelihood ratio test, and bootstrapped likelihood ratio test (BLRT) verification and composition ratio distribution using potential profiles were comprehensively considered. Second, to examine if there was a difference between problem behavior and executive function according to the class of media device addiction identified in the potential profile analysis, a one-way analysis of variance was performed. To explore the association between different classes of problematic media device user and behavioral problems, logistic regression was performed with 65 or more cutoff points for each CBCL subscale as dependent variables and sex and maternal education as covariates. In further analysis, suicidal thoughts were assessed using CBCL item 91, "Talks about killing self," and suicidal behavior was assessed using CBCL item 18, "Deliberately harms self or attempts suicide." Analyses were performed using SPSS (version 21.0; IBM Corp., Armonk, NY, USA) and M plus version 7.0 (Muthén \& Muthén, Los Angeles, CA). Statistical significance was defined as a p-value of $<0.05$.

\section{RESULTS}

\section{Determining the number of classes}

Latent profile analysis was conducted to determine the num- ber of classes of problematic media device user group, and the results are shown in Table 1. To determine the optimal model, this study examined the changes in model fitness by sequentially increasing the number of hierarchies from two latent hierarchical models. The AIC and aBIC values of each latent layer model decreased until the number of latent profiles was six, and the entropy was higher than $0.80 .{ }^{17}$ In addition, if the BLRT and VLMR-LRT are significant, it means that the k group is superior to the k-1 group in terms of fitness. ${ }^{30}$ Of the six models, two, three, and four latent models were found to be statistically significant. In addition, two to four models were found to be satisfactory for the condition that can be compared by class when the proportion of the classified subgroups in the entire sample is at least 5\%. ${ }^{16}$ Therefore, in this study, three class models were finally selected considering the information criteria, entropy value, statistical significance test, ratio of cases, conceptual explanation of class, and actual application points.

\section{Demographic characteristics of problematic media device user}

Out of a total of 1,389, 339 children had an Internet addiction scale score of 28 or higher, comprising 211 boys (62.24\%) and 128 girls (37.76\%). Table 2 shows the results of comparing the demographic characteristics of a total of four groups (three identified classes of problematic media device users and a control group). In the control group, there were 491 boys (46.76\%), whereas boys accounted for more than $60 \%$ of each of the three classes of problematic media device users, indicating that there was a statistically significant difference in sex distribution between the groups $(\mathrm{p}<0.001)$.

There was no significant difference between the four groups in terms of parental age. Maternal education level showed a significant difference between the groups $(\mathrm{p}<0.001)$. In the control group, high school graduate or lower accounted for only approximately $23.90 \%$ of mothers, whereas in classes 1,2 , and 3 , it accounted for $47.06 \%, 36.96 \%$, and $32.67 \%$ of mothers, respectively. There was no significant difference between groups in terms of paternal education level or household income.

Table 1. Determination of model selection

\begin{tabular}{cccccccl}
\hline No. of classes & AIC & BIC & aBIC & Entropy & VLMR-LRT & BLRT & Group ratio (\%) \\
\hline 2 & $8,990.64$ & $9,338.81$ & $9,050.14$ & 0.863 & 0.00 & 0.00 & $54.57 / 45.43$ \\
3 & $8,779.95$ & $9,304.11$ & $8,869.53$ & 0.877 & 0.09 & 0.00 & $15.04 / 40.71 / 44.25$ \\
4 & $8,614.25$ & $9,314.41$ & $8,733.90$ & 0.900 & 0.08 & 0.00 & $11.50 / 37.76 / 36.87 / 13.86$ \\
5 & $8,515.44$ & $9,391.59$ & $8,665.17$ & 0.929 & 0.81 & 0.00 & $5.90 / 38.05 / 4.72 / 12.09 / 39.23$ \\
6 & $8,467.84$ & $9,519.99$ & $8,647.64$ & 0.926 & 0.76 & 0.00 & $5.90 / 15.04 / 28.02 / 41.00 / 3.84 / 6.20$ \\
\hline
\end{tabular}

AIC, Akaike information criterion; BIC, Bayesian information criterion; aBIC, sample-size adjusted BIC; VLMR-LRT, Vuong-Lo-MendellRubin likelihood ratio test; BLRT, bootstrap likelihood ratio test 


\section{Characteristics of classes of problematic media device user}

Statistically significant differences were found in all media device addiction severity according to the class of problematic media device user, and the results of addiction severity comparison are shown in Table 3. Class 1 accounted for the lowest proportion (15.04\%) of high-risk media device users among the three classes and had higher scores in areas of daily activity disturbance, withdrawal, and tolerance than the other two classes. Second, class 2 accounted for $40.71 \%$ of high-risk media device users, and the scores of daily activity disturbance and tolerance were lower than those of class 1 and higher than the scores of class 3 . In terms of withdrawal, there was a significant difference compared to that in class 1 , but there was no significant difference compared to that in class 3 . Lastly, class 3 ac- counted for $44.25 \%$ of high-risk media device users, and the scores in the areas of daily activity disturbance, tolerance, and total severity were the lowest among the three classes. In a posthoc test, there was no significant difference in the withdrawal score compared to that in class 2. Overall, compared to the control group, all classes had significantly higher media device addiction severity on all scales.

\section{Differences in executive function difficulty according to class of problematic media device user}

According to the class of problematic media device user, statistically significant differences were found in all four subscales of difficulty in execution function, and the analysis results are shown in Table 4. Class 1 had higher scores in the areas of planning-organization difficulty, behavior control difficulty, emo-

Table 2. Demographic characteristics of problematic media device user

\begin{tabular}{|c|c|c|c|c|c|}
\hline & Class $1(\mathrm{~N}=51)$ & Class $2(\mathrm{~N}=138)$ & Class $3(\mathrm{~N}=150)$ & Control $(\mathrm{N}=1,050)$ & p-value \\
\hline Male, N (\%) & $35(68.63)$ & $84(60.87)$ & $92(61.33)$ & $491(46.76)$ & $<0.001$ \\
\hline Maternal age, mean (SD) & $39.64(4.64)$ & $40.28(3.56)$ & $39.50(3.65)$ & $39.81(3.59)$ & 0.330 \\
\hline Paternal age, mean (SD) & $42.37(4.51)$ & $42.79(3.98)$ & $41.85(3.93)$ & $42.21(3.91)$ & 0.240 \\
\hline Maternal education, $\mathrm{N}(\%)$ & & & & & $<0.001$ \\
\hline High school graduate or lower & $24(47.06)$ & $51(36.96)$ & $49(32.67)$ & $251(23.90)$ & \\
\hline University graduate & $26(50.98)$ & $78(56.52)$ & $94(62.67)$ & $723(68.86)$ & \\
\hline Postgraduate & $1(1.96)$ & $7(5.07)$ & $7(4.67)$ & $72(6.86)$ & \\
\hline No response & $0(0)$ & $2(1.45)$ & $0(0)$ & $4(0.38)$ & \\
\hline Paternal education, N (\%) & & & & & 0.720 \\
\hline High school graduate or lower & $18(35.29)$ & $39(28.26)$ & $46(30.67)$ & $264(25.14)$ & \\
\hline University graduate & $29(56.86)$ & $85(61.59)$ & $89(59.33)$ & $655(62.38)$ & \\
\hline Postgraduate & $4(7.84)$ & $13(9.42)$ & $14(9.33)$ & $126(12.00)$ & \\
\hline No response & $0(0)$ & $1(0.72)$ & $1(0.67)$ & $5(0.48)$ & \\
\hline Household income, N (\%) & & & & & 0.564 \\
\hline Low & $5(9.80)$ & $15(10.87)$ & $14(9.33)$ & $71(6.76)$ & \\
\hline Intermediate & 39 (76.47) & $95(68.84)$ & $109(72.67)$ & $772(73.52)$ & \\
\hline High & $4(7.84)$ & $11(7.97)$ & $16(10.67)$ & $101(9.62)$ & \\
\hline No response & $3(5.88)$ & $17(12.32)$ & $11(7.33)$ & $106(10.10)$ & \\
\hline
\end{tabular}

Table 3. Media device addiction severity among four groups $(\mathrm{N}=1,389)$

\begin{tabular}{lccccccc}
\hline \multicolumn{1}{c}{ Variables } & $\begin{array}{c}\text { Class 1 } \\
(\mathrm{N}=51)\end{array}$ & $\begin{array}{c}\text { Class 2 } \\
(\mathrm{N}=138)\end{array}$ & $\begin{array}{c}\text { Class 3 } \\
(\mathrm{N}=150)\end{array}$ & $\begin{array}{c}\text { Control } \\
(\mathrm{N}=1,050)\end{array}$ & F & p-value & Post hoc level \\
\hline $\begin{array}{l}\text { Daily activity disturbance (scores), } \\
\text { mean (SD) }\end{array}$ & $12.12(1.99)$ & $10.39(0.97)$ & $9.36(1.45)$ & $6.28(1.18)$ & 929.88 & $<0.001^{*}$ & $1>2>3>\mathrm{C}$ \\
Withdrawal (scores), mean (SD) & $10.63(1.87)$ & $8.76(0.89)$ & $8.97(1.40)$ & $6.37(1.45)$ & 348.92 & $<0.001^{*}$ & $1>2,3>\mathrm{C}$ \\
Tolerance (scores), mean (SD) & $9.08(2.00)$ & $8.43(0.97)$ & $7.11(1.12)$ & $5.26(1.27)$ & 430.87 & $<0.001^{*}$ & $1>2>3>\mathrm{C}$ \\
$\begin{array}{l}\text { Total media device addiction severity } \\
\text { (scores), mean (SD) }\end{array}$ & $38.06(4.92)$ & $32.13(2.15)$ & $30.20(2.12)$ & $20.88(3.32)$ & $1,150.56$ & $<0.001^{*}$ & $1>2>3>\mathrm{C}$ \\
\hline
\end{tabular}

${ }^{*} \mathrm{p}<0.001 . \mathrm{SD}$, standard deviation 
tional control difficulty, and inattention than those of the other classes. As a result of the post-test, class 1 had significantly higher scores for executive function difficulties than those in classes 2 and 3. Class 2 had lower scores on the executive function difficulties subscale compared to those in classes 1 and 3 . The scores of class 3 for each subscale were lower than those of class 1 and higher than those of class 2 . The post hoc test showed no significant difference between classes 2 and 3. Overall, compared to the control group, all classes had significantly more severe executive function difficulties according to all subscales.

\section{Child behavioral problems according to class of problematic media device user}

Behavioral problems were among 339 problematic media device user compared based on the class of problematic media device user (Table 5). There were significant statistical differences between the three classes in all subscales of the CBCL except for the anxious/depressed, somatization, and thought problems subscales. Class 1 reported had the most severe total, externalizing, withdrawn/depressed, immature, attention, rule-breaking, and aggressive behavior problems among the three classes. For all subscales of the CBCL, there were no significant differences between classes 2 and 3. Overall, compared to the control group, all classes had significantly more severe behavioral problems based on the total, externalizing, withdrawn/depressed, and rule-breaking subscales.

\section{Associations between classes of problematic media device user and CBCL subscales}

In logistic regression analysis, total, internalizing, anxious/ depressed, and immature problems were more frequent in class 1 than in the control group (Table 6). Externalizing, rule-breaking, aggressive behavior, and thought problems were more frequent in class 1 and class 3 than in the control group. Withdrawn/depressed and attention problems were more frequent in class 1 and in class 2 than in the control group. In a further analysis to investigate the association between suicidal behav-

Table 4. Comparison of executive function difficulties among four groups $(\mathrm{N}=1,389)$

\begin{tabular}{|c|c|c|c|c|c|c|}
\hline Variables & $\begin{array}{l}\text { Class } 1 \\
(\mathrm{~N}=51)\end{array}$ & $\begin{array}{c}\text { Class } 2 \\
(\mathrm{~N}=138)\end{array}$ & $\begin{array}{l}\text { Class } 3 \\
(\mathrm{~N}=150)\end{array}$ & $\begin{array}{c}\text { Control } \\
(\mathrm{N}=1,050)\end{array}$ & $\mathrm{F}$ & Post hoc level \\
\hline $\begin{array}{l}\text { Planning-organization difficulties (scores), } \\
\text { mean (SD) }\end{array}$ & $23.16(5.40)$ & $19.63(4.62)$ & $20.11(4.78)$ & $17.21(4.48)$ & $46.06^{*}$ & $1>2,3>C$ \\
\hline Behavior control difficulties (scores), mean (SD) & $18.75(4.54)$ & $14.75(3.37)$ & $15.46(3.96)$ & $13.39(2.91)$ & $64.80^{*}$ & $1>2,3>C$ \\
\hline Emotional control difficulties (scores), mean (SD) & $15.24(4.57)$ & $12.17(4.08)$ & $12.99(3.80)$ & $11.06(3.29)$ & $35.75^{*}$ & $1>2,3>C$ \\
\hline $\begin{array}{l}\text { Attention-concentration difficulties (scores), } \\
\text { mean (SD) }\end{array}$ & $19.86(5.43)$ & $16.96(5.08)$ & $17.55(4.70)$ & $14.72(4.12)$ & $44.60^{*}$ & $1>2,3>C$ \\
\hline
\end{tabular}

${ }^{*} \mathrm{p}<0.001$. SD, standard deviation

Table 5. Comparison of behavioral problems between four groups $(\mathrm{N}=1,389)$

\begin{tabular}{|c|c|c|c|c|c|c|}
\hline Variables & Class $1(\mathrm{~N}=51)$ & Class $2(\mathrm{~N}=138)$ & Class $3(\mathrm{~N}=150)$ & Control $(\mathrm{N}=1,050)$ & $\mathrm{F}$ & Post hoc level \\
\hline Total & $56.33(11.30)$ & $49.79(10.92)$ & $51.65(8.92)$ & $47.05(9.88)$ & $23.17^{*}$ & $1>2,3>C$ \\
\hline Internalizing & $54.86(9.75)$ & $50.20(10.08)$ & $50.83(8.55)$ & $47.91(8.94)$ & $14.53^{*}$ & $\begin{array}{c}1,3>C \\
1>2\end{array}$ \\
\hline Externalizing & $56.55(10.38)$ & $50.50(9.40)$ & $52.18(8.88)$ & $48.20(8.86)$ & $22.26^{*}$ & $1>2,3>C$ \\
\hline Anxious/depressed & $56.00(6.39)$ & $54.18(6.12)$ & $54.27(5.49)$ & $53.00(5.36)$ & $7.82^{*}$ & $1>C$ \\
\hline Withdrawn/depressed & $57.98(8.29)$ & $54.18(5.36)$ & $54.27(5.30)$ & $52.78(4.98)$ & $20.22^{*}$ & $1>2,3>C$ \\
\hline Somatization & $55.45(6.71)$ & $53.29(5.66)$ & $53.52(5.13)$ & $52.73(4.90)$ & $5.61^{*}$ & $1>\mathrm{C}$ \\
\hline Immature & $58.39(7.09)$ & $53.81(5.41)$ & $54.29(5.27)$ & $53.01(5.18)$ & $18.67^{*}$ & $1>2,3, C$ \\
\hline Thought problem & $56.41(7.05)$ & $54.28(6.19)$ & $54.77(5.78)$ & $53.36(5.43)$ & $7.60^{*}$ & $1,3>C$ \\
\hline Attention problem & $57.16(6.84)$ & $53.28(4.96)$ & $53.89(5.06)$ & $52.17(4.79)$ & $21.43^{*}$ & $\begin{array}{c}1>3>C \\
1>2\end{array}$ \\
\hline Rule-breaking & $58.84(6.87)$ & $55.07(5.20)$ & $55.27(5.44)$ & $53.39(4.93)$ & $24.86^{*}$ & $1>2,3>C$ \\
\hline Aggressive behavior & $57.24(7.74)$ & $53.69(5.45)$ & $54.51(5.45)$ & $52.63(5.00)$ & $17.69^{*}$ & $\begin{array}{c}1>3>C \\
1>2\end{array}$ \\
\hline Miscellaneous & $57.16(7.10)$ & $54.87(6.40)$ & $55.27(5.63)$ & $53.44(5.65)$ & $11.69^{*}$ & $1,3>C$ \\
\hline
\end{tabular}

${ }^{*} \mathrm{p}<0.001$ 
Table 6. Results of logistic regression for associations between classes of problematic media device user and $\mathrm{CBCL}$ subscales

\begin{tabular}{|c|c|c|c|c|}
\hline Variable & $\beta(\mathrm{SE})$ & $\mathrm{aOR}$ & $95 \% \mathrm{CI}$ & p-value \\
\hline \multicolumn{5}{|c|}{ CBCL 6-18 subscales at 9 years } \\
\hline \multicolumn{5}{|l|}{ Total problem } \\
\hline Class 1 & $1.59(0.46)$ & 4.89 & $1.39-11.98$ & $<0.001$ \\
\hline Class 2 & $0.20(0.50)$ & 1.22 & $0.46-3.21$ & 0.694 \\
\hline Class 3 & $0.09(0.49)$ & 1.10 & $0.42-2.88$ & 0.853 \\
\hline \multicolumn{5}{|l|}{ Control } \\
\hline \multicolumn{5}{|l|}{ Internalizing } \\
\hline Class 1 & $1.53(0.43)$ & 4.63 & $2.00-10.70$ & $<0.001$ \\
\hline Class 2 & $0.58(0.39)$ & 1.78 & $0.84-3.78$ & 0.134 \\
\hline Class 3 & $-0.15(0.49)$ & 0.86 & $0.33-2.22$ & 0.753 \\
\hline \multicolumn{5}{|l|}{ Control } \\
\hline \multicolumn{5}{|l|}{ Externalizing } \\
\hline Class 1 & $1.68(0.44)$ & 5.38 & $2.29-12.61$ & $<0.001$ \\
\hline Class 2 & $0.44(0.43)$ & 1.64 & $0.70-3.81$ & 0.254 \\
\hline Class 3 & $0.87(0.37)$ & 2.39 & $1.17-4.88$ & 0.017 \\
\hline \multicolumn{5}{|l|}{ Control } \\
\hline \multicolumn{5}{|c|}{ Anxious/depressed } \\
\hline Class 1 & $1.09(0.42)$ & 2.97 & $1.30-6.83$ & 0.010 \\
\hline Class 2 & $0.51(0.34)$ & 1.66 & $0.85-3.24$ & 0.139 \\
\hline Class 3 & $0.18(0.36)$ & 1.20 & $0.59-2.43$ & 0.623 \\
\hline \multicolumn{5}{|l|}{ Control } \\
\hline \multicolumn{5}{|c|}{ Withdrawn/depressed } \\
\hline Class 1 & $1.86(0.39)$ & 6.43 & $3.01-13.75$ & $<0.001$ \\
\hline Class 2 & $0.76(0.36)$ & 2.14 & $1.06-4.32$ & 0.034 \\
\hline Class 3 & $0.17(0.43)$ & 1.19 & $0.52-2.72$ & 0.684 \\
\hline \multicolumn{5}{|l|}{ Control } \\
\hline \multicolumn{5}{|l|}{ Somatization } \\
\hline Class 1 & $0.97(0.51)$ & 2.64 & $0.97-7.17$ & 0.057 \\
\hline Class 2 & $-0.05(0.49)$ & 0.96 & $0.37-2.49$ & 0.927 \\
\hline Class 3 & $0.20(0.43)$ & 1.22 & $0.53-2.81$ & 0.634 \\
\hline \multicolumn{5}{|l|}{ Control } \\
\hline \multicolumn{5}{|c|}{ Immature behavior } \\
\hline Class 1 & $1.34(0.43)$ & 3.80 & $1.65-8.76$ & 0.002 \\
\hline Class 2 & $-0.21(0.49)$ & 0.81 & $0.31-2.10$ & 0.665 \\
\hline Class 3 & $0.17(0.40)$ & 1.18 & $0.54-2.58$ & 0.672 \\
\hline \multicolumn{5}{|l|}{ Control } \\
\hline \multicolumn{5}{|c|}{ Rule-breaking behavior } \\
\hline Class 1 & $1.59(0.40)$ & 12.95 & $6.61-25.38$ & $<0.001$ \\
\hline Class 2 & $-0.46(0.44)$ & 1.74 & $0.82-3.70$ & 0.148 \\
\hline Class 3 & $1.00(0.32)$ & 2.72 & $1.46-5.09$ & 0.002 \\
\hline Control & & & & \\
\hline
\end{tabular}

Table 6. Results of logistic regression for associations between classes of problematic media device user and CBCL subscales (continued)

\begin{tabular}{lcccc}
\hline Variable & $\beta(\mathrm{SE})$ & $\mathrm{aOR}$ & $95 \% \mathrm{CI}$ & $\mathrm{p}$-value \\
\hline Aggressive behavior & & & & \\
Class 1 & $1.04(0.51)$ & 2.83 & $1.04-7.73$ & 0.042 \\
Class 2 & $0.56(0.41)$ & 1.75 & $0.78-3.90$ & 0.174 \\
Class 3 & $0.80(0.36)$ & 2.23 & $1.09-4.54$ & 0.028 \\
Control & & & & \\
Thought problem & & & & \\
Class 1 & $1.59(0.39)$ & 4.90 & $2.28-10.54$ & $<0.001$ \\
Class 2 & $0.45(0.36)$ & 1.57 & $0.77-3.19$ & 0.212 \\
Class 3 & $0.76(0.31)$ & 2.14 & $1.17-3.94$ & 0.014 \\
Control & & & &
\end{tabular}

Attention problem

$\begin{array}{llrlr}\text { Class 1 } & 2.39(0.43) & 10.89 & 4.74-25.06 & <0.001 \\ \text { Class 2 } & 0.88(0.45) & 2.42 & 1.01-5.80 & 0.048 \\ \text { Class 3 } & 0.42(0.50) & 1.52 & 0.56-4.07 & 0.409 \\ \text { Control } & & & & \end{array}$

Suicidal ideation

$\begin{array}{lllll}\text { Class } 1 & 1.19(0.44) & 3.29 & 1.38-7.81 & 0.007\end{array}$

$\begin{array}{lllll}\text { Class } 2 & 0.37(0.38) & 1.45 & 0.69-3.06 & 0.325\end{array}$

$\begin{array}{lllll}\text { Class } 3 & 0.50(0.35) & 1.64 & 0.83-3.26 & 0.155\end{array}$

Control

Suicidal behavior

\begin{tabular}{lllll} 
Class 1 & $1.16(0.32)$ & 3.20 & $1.72-5.94$ & $<0.001$ \\
Class 2 & $0.47(0.19)$ & 1.61 & $1.11-2.32$ & 0.011 \\
Class 3 & $0.54(0.18)$ & 1.71 & $1.20-2.44$ & 0.003 \\
Control & & & & \\
\hline
\end{tabular}

Adjusted for sex and maternal education level. ${ }^{*} \mathrm{p}<0.05$. CBCL, Child behavior Checklist

ior and classes of problematic media device use, class 1 more frequently had suicidal ideation ( $\mathrm{p}=0.007$, adjusted odds ratio [OR]: 3.29, 95\% confidence interval [CI]: 1.38-7.81) than the control group, and suicidal behavior was more frequent in class 1 ( $<<0.001$, adjusted OR: 3.20, 95\% CI: 1.72-5.94), class 2 ( $\mathrm{p}=$ 0.011 , adjusted OR: $1.61,95 \%$ CI: $1.11-2.32)$, and class 3 ( $\mathrm{p}=$ 0.003 , adjusted OR: $1.71,95 \%$ CI: $1.20-2.44)$ than in the control group.

\section{DISCUSSION}

In this study, three classes were identified in children with problematic media device use. Class 1 had significantly more severe daily activity disturbance, tolerance, and withdrawal than other classes. Behavioral problems and executive function difficulties were most severe in class 1 . Classes 2 and 3 had less severe media device addiction scores than class 1 , and execu- 
tive function difficulties and behavioral problems were also significantly less severe than those in class 1 .

Class 1 accounted for 51 out of 1,484 (3.44\%), which is similar to the Internet addiction prevalence rate of 5\% reported in previous studies. ${ }^{31,32}$ In our study, class 1 children had significantly more severe externalizing problems, including aggressive behavior and rule-breaking behavior, than those of other classes. Although types of media device usage (e.g., social media service, video watching, education, and entertainment) and content were not investigated, we confirmed an association between problematic media device use and externalizing problems. This is consistent with the finding that aggressive behaviors in children with smartphone overuse are associated with usage time. ${ }^{33}$ In a recently published prospective study, hostility worsened during Internet addiction among adolescents. ${ }^{34}$ In particular, one study reported that reducing media is effective in decreasing aggressive behavior in elementary schoolaged children. ${ }^{35}$ Therefore, it is necessary to provide appropriate parental guidance regarding children's media device usage.

Previous studies have reported high levels of anxiety, depression, and social withdrawal in adolescents with Internet addiction. ${ }^{36-38}$ In our study, it was confirmed that the internalizing problem increased as the symptom severity of problematic media device use in children increased, which is consistent with the results of longitudinal studies of adolescents with Internet addiction. ${ }^{39}$ In class 1, suicidal ideation was significantly more frequent than in the control group, and suicidal behavior was significantly more frequent in all classes compared than in the control group. A growing body of evidence suggests that Internet addiction is associated with increased suicidality. ${ }^{40,41} \mathrm{It}$ has been reported that among individuals with Internet addiction, adolescents under the age of 18 have more frequent suicidal ideation than adults. ${ }^{42} \mathrm{~A}$ recent large-scale study also provided evidence that adolescents with Internet addiction more frequently had non-suicidal self-injury. ${ }^{43}$ Although the peak onset of non-suicidal self-injury occurs after 13 years of age, our study confirmed the association between suicidal behavior and problematic media device use in prepubertal children. ${ }^{44}$

In our study, a high level of executive function difficulty was demonstrated in the highest problematic media device use class, which corroborates previous studies. ${ }^{45,46}$ Compared to class 1 , class 2 and class 3, which were the subgroups with less severe media device addiction, also showed significant difficulties in executive function relative to the control group. Studies on Internet addiction and neurocognitive characteristics suggest that Internet addiction persists due to the loss of behavioral inhibitory control, disadvantageous decision making against predicted negative outcomes, and decreased mental flexibility related to changes in the activation of specific brain regions. ${ }^{4-49}$ However, since the results of this study cannot identify the causal relationship between the impairment of executive function and media device addiction, a prospective study on this should be performed.

Regarding the addiction scale, class 2 had a higher score for daily life disturbance and tolerance than those of class 3 , but there was no significant difference between classes 2 and 3 with respect to the withdrawal subscale. Classes 2 and 3 had no significant differences in executive function difficulties despite the difference in addiction scale. In class 2, suicidal behavior, withdrawn/depressed, and attention problems were significantly more common than in the control group, and in class 3, rulebreaking, aggressive behavior, thought, and externalizing problems were more common than in the control group. In sum, class 2 is characterized by depressive symptoms and attention problems, and class 3 can be characterized by externalizing problems as the main manifestation. Although media device addiction severity was lower in class 3 than in class 2, externalizing problems were higher than in class 2. A possible explanation for this is that although there was no statistically significant difference between class 2 and class 3, it may reflect the greater executive function difficulties of class 3 . Therefore, children with problematic media device use may have behavioral problems according to the severity of addiction, and even in children with mild media device addiction levels, careful screening of aggressive behaviors may be clinically useful.

Among children with media device addiction, children in classes 1 or $2(n=189,55.75 \%)$ were more likely to be included in the clinical risk group for CBCL attention problems (cutoff $\geq 65 \mathrm{~T}$ score) than those in the control group. In a previous study, $\mathrm{ADHD}$ was reported to be a common comorbidity in Internet addiction..$^{50} \mathrm{~A}$ possible explanation for this finding is that because of the "easy to bore" and "aversion to delayed reward" features of ADHD, it would be easy to abuse the Internet, which gives an immediate and interesting response. ${ }^{51}$ Conversely, problematic media device use may have contributed to attentional problems. ${ }^{52}$

This study had several limitations. First, as this study was a cross-sectional design study, the causal relationship between variables could not be confirmed. Second, no information was collected on the quantitative use of the media device, purpose of use, type of use, or environment of use.

In conclusion, we confirmed three subtypes of children with problematic media device use. Behavioral problems and executive function difficulties were most severe in the subtype with the highest media device addiction severity. Also, even in children with mild media device addition, significant levels of externalizing behavior were observed. Problematic media device use is highly correlated with mental illness in children and adolescents, and careful screening and clinical attention are required in the children with problematic media device use. Fu- 
ture research should determine whether the contents of media device use and parental supervision can reduce the burden of mental health conditions.

\section{Availability of Data and Material}

The datasets generated or analyzed during the study are available from the corresponding author on reasonable request.

\section{Conflicts of Interest}

The authors have no potential conflicts of interest to disclose.

\section{Author Contributions}

Conceptualization: Yunhye Oh, Yoo-Sook Joung. Data curation: Yunhye Oh. Formal analysis: Yunhye Oh, Youngmi Kim. Investigation: all authors. Supervision: Yoo-Sook Joung. Writing-original draft: Yunhye Oh, YooSook Joung. Writing_review \& editing: all authors.

\section{ORCID iDs}

Yunhye Oh

Youngmi Kim

https://orcid.org/0000-0002-5945-2621

Yoo-Sook Joung

\section{Funding Statement}

None.

\section{Acknowledgments}

On behalf of all authors, the corresponding author states that there are no conflicts of interest. The findings and conclusions of this study are those of the authors and do not necessarily represent the views of the funding agency. The authors declare no competing financial interests. The results of the present study do not constitute endorsement by "Psychiatry Investigation."

\section{REFERENCES}

1. Goggin G. Cell Phone Culture: Mobile Technology in Everyday Life. London: Routledge; 2006.

2. Wei R. Motivations for using the mobile phone for mass communications and entertainment. Telemat Inform 2008;25:36-46.

3. Adelantado-Renau M, Moliner-Urdiales D, Cavero-Redondo I, Beltran-Valls MR, Martínez-Vizcaíno V, Álvarez-Bueno C. Association between screen media use and academic performance among children and adolescents: a systematic review and meta-analysis. JAMA pediatr 2019; 173:1058-1067.

4. Cain N, Gradisar M. Electronic media use and sleep in school-aged children and adolescents: a review. Sleep Med 2010;11:735-742.

5. Mendoza JA, Zimmerman FJ, Christakis DA. Television viewing, computer use, obesity, and adiposity in US preschool children. Int J Behav Nutr Phys Act 2007;4:44.

6. Bickham DS, Hswen Y, Rich M. Media use and depression: exposure, household rules, and symptoms among young adolescents in the USA. Int J Public Health 2015;60:147-155.

7. Cao X, Masood A, Luqman A, Ali A. Excessive use of mobile social networking sites and poor academic performance: antecedents and consequences from stressor-strain-outcome perspective. Comput $\mathrm{Hu}$ man Behav 2018;85:163-174.

8. Lee HW, Choi JS, Shin YC, Lee JY, Jung HY, Kwon JS. Impulsivity in internet addiction: a comparison with pathological gambling. Cyberpsychol Behav Soc Netw 2012;15:373-377.

9. Yen JY, Yen CF, Chen CS, Tang TC, Ko CH. The association between adult ADHD symptoms and internet addiction among college students: the gender difference. Cyberpsychol Behav 2009;12:187-191.

10. Keles B, McCrae N, Grealish A. A systematic review: the influence of social media on depression, anxiety and psychological distress in ado-

lescents. Int J Adolesc Youth 2020;25:79-93.

11. Petry NM, Rehbein F, Gentile DA, Lemmens JS, Rumpf HJ, Mößle T, et al. An international consensus for assessing internet gaming disorder using the new DSM-5 approach. Addiction 2014;109:1399-1406.

12. Yen JY, Liu TL, Wang PW, Chen CS, Yen CF, Ko CH. Association between Internet gaming disorder and adult attention deficit and hyperactivity disorder and their correlates: Impulsivity and hostility. Addict Behav 2017;64:308-313.

13. Hawi NS, Samaha M, Griffiths MD. Internet gaming disorder in Lebanon: relationships with age, sleep habits, and academic achievement. J Behav Addict 2018;7:70-78.

14. Yoo HJ, Cho SC, Ha J, Yune SK, Kim SJ, Hwang J, et al. Attention deficit hyperactivity symptoms and internet addiction. Psychiatry Clin Neurosci 2004;58:487-494.

15. Kim SG, Park J, Kim HT, Pan Z, Lee Y, McIntyre RS. The relationship between smartphone addiction and symptoms of depression, anxiety, and attention-deficit/hyperactivity in South Korean adolescents. Ann Gen Psychiatry 2019;18:1.

16. Jung T, Wickrama KA. An introduction to latent class growth analysis and growth mixture modeling. Soc Pers Psychol Compass 2008;2:302317.

17. Muthén B. The Sage Handbook of Quantitative Methodology for the Social Sciences. chap. 19 Latent Variable Analysis: Growth Mixture Modeling and Related Techniques for Longitudinal Data. Newbury Park, CA: Sage Publications, 2004. p.345-368.

18. Cerniglia L, Griffiths MD, Cimino S, De Palo V, Monacis L, Sinatra M, et al. A latent profile approach for the study of internet gaming disorder, social media addiction, and psychopathology in a normative sample of adolescents. Psychol Res Behav Manag 2019;12:651-659.

19. Mok JY, Choi SW, Kim DJ, Choi JS, Lee J, Ahn H, et al. Latent class analysis on internet and smartphone addiction in college students. Neuropsychiatr Dis Treat 2014;10:817-828.

20. Foerster M, Röösli M. A latent class analysis on adolescents media use and associations with health related quality of life. Comput Human Behav 2017;71:266-274.

21. Kim D, Nam JK, Oh J, Kang MC. A latent profile analysis of the interplay between PC and smartphone in problematic internet use. Comput Human Behav 2016;56:360-368.

22. Scott CF, Bay-Cheng LY, Prince MA, Nochajski TH, Collins RL. Time spent online: latent profile analyses of emerging adults's social media use. Comput Human Behav 2017;75:311-319.

23. Bahk J, Yun SC, Kim YM, Khang YH. Impact of unintended pregnancy on maternal mental health: a causal analysis using follow up data of the Panel Study on Korean Children (PSKC). BMC Pregnancy Childbirth 2015;15:85.

24. Cho H, Kwon M, Choi JH, Lee SK, Choi JS, Choi SW, et al. Development of the Internet addiction scale based on the Internet Gaming Disorder criteria suggested in DSM-5. Addict Behav 2014;39:1361-1366.

25. Koo H, Cho S, Kwon J. A study for examining diagnostic ability of the $\mathrm{K}-\mathrm{Scale}$ as a diagnostic tool for DSM-5 internet gaming disorder. Korean J Clin Psychol 2015;34:335-352.

26. Shin G, Kim D, Jeon Y, Lee J, Lee Y, Kim M. Third Standardization of Korean Internet Addiction Proneness Scale. Seoul: National Information Society Agency; 2011 November. Report No. NIA IV-RER-11050.

27. Achenbach TM, Rescorla L. Manual for the ASEBA School-Age Forms \& Profiles: An Integrated System of Multi-Informant Assessment. Burlington, VT: Aseba; 2001.

28. Oh K, Kim Y, Ha E, Lee H, Hong K. Korean Version of Child Behavior Checklist for Ages 6-18. Seoul: Huno; 2010.

29. Song H. Validity of child-adolescent self-reported executive function difficulty screening questionnaire. Korean J Clin Psychol 2014;33:121137.

30. Pastor DA, Barron KE, Miller B, Davis SL. A latent profile analysis of college students' achievement goal orientation. Contemporary Educ Psychol 2007;32:8-47. 
31. Cheng C, Li AY. Internet addiction prevalence and quality of (real) life: a meta-analysis of 31 nations across seven world regions. Cyberpsychol Behav Soc Netw 2014;17:755-760.

32. Fu KW, Chan WS, Wong PW, Yip PS. Internet addiction: prevalence, discriminant validity and correlates among adolescents in Hong Kong. Br J Psychiatry 2010;196:486-492.

33. Baek HW, Shin YM, Shin KM. Emotional and behavioral problems related to smartphone overuse in elementary school children. J Korean Neuropsychiatr Assoc 2014;53:320-326.

34. Ko CH, Liu TL, Wang PW, Chen CS, Yen CF, Yen JY. The exacerbation of depression, hostility, and social anxiety in the course of Internet addiction among adolescents: a prospective study. Compr Psychiatry 2014; 55:1377-1384.

35. Robinson TN, Wilde ML, Navracruz LC, Haydel KF, Varady A. Effects of reducing children's television and video game use on aggressive behavior: a randomized controlled trial. Arch Pediatr Adolesc Med 2001; 155:17-23.

36. Ko CH, Yen JY, Chen CS, Yeh YC, Yen CF. Predictive values of psychiatric symptoms for internet addiction in adolescents: a 2-year prospective study. Arch Pediatr Adolesc Med 2009;163:937-943.

37. Cho SM, Sung MJ, Shin KM, Lim KY, Shin YM. Does psychopathology in childhood predict internet addiction in male adolescents? Child Psychiatry Hum Dev 2013;44:549-555.

38. Elhai JD, Dvorak RD, Levine JC, Hall BJ. Problematic smartphone use: a conceptual overview and systematic review of relations with anxiety and depression psychopathology. J Affect Disord 2017;207:251-259.

39. Riehm KE, Feder KA, Tormohlen KN, Crum RM, Young AS, Green $\mathrm{KM}$, et al. Associations between time spent using social media and internalizing and externalizing problems among US youth. JAMA Psychiatry 2019;76:1266-1273.

40. Shen Y, Meng F, Xu H, Li X, Zhang Y, Huang C, et al. Internet addiction among college students in a Chinese population: prevalence, correlates, and its relationship with suicide attempts. Depress Anxiety 2020; 37:812-821.

41. Pan PY, Yeh CB. Internet addiction among adolescents may predict self-harm/suicidal behavior: a prospective study. J Pediatr 2018;197: 262-267.
42. Cheng YS, Tseng PT, Lin PY, Chen TY, Stubbs B, Carvalho AF, et al. Internet addiction and its relationship with suicidal behaviors: a metaanalysis of multinational observational studies. J Clin Psychiatry 2018; 79:17r11761.

43. Tang J, Ma Y, Lewis SP, Chen R, Clifford A, Ammerman BA, et al. Association of internet addiction with nonsuicidal self-injury among adolescents in China. JAMA Netw Open 2020;3:e206863.

44. Gandhi A, Luyckx K, Baetens I, Kiekens G, Sleuwaegen E, Berens A, et al. Age of onset of non-suicidal self-injury in Dutch-speaking adolescents and emerging adults: an event history analysis of pooled data. Compr Psychiatry 2018;80:170-178.

45. Kuo SY, Chen YT, Chang YK, Lee PH, Liu MJ, Chen SR. Influence of internet addiction on executive function and learning attention in Taiwanese school-aged children. Perspect Psychiatr Care 2018;54:495500.

46. Hyun GJ, Han DH, Lee YS, Kang KD, Yoo SK, Chung US, et al. Risk factors associated with online game addiction: a hierarchical model. Comput Human Behav 2015;48:706-713.

47. Pawlikowski M, Brand M. Excessive Internet gaming and decision making: do excessive World of Warcraft players have problems in decision making under risky conditions? Psychiatry Res 2011;188:428-433.

48. Dong G, Lin X, Zhou H, Lu Q. Cognitive flexibility in internet addicts: fMRI evidence from difficult-to-easy and easy-to-difficult switching situations. Addict Behav 2014;39:677-683.

49. Dong G, Hu Y, Lin X, Lu Q. What makes Internet addicts continue playing online even when faced by severe negative consequences? Possible explanations from an fMRI study. Biol Psychol 2013;94:282-289.

50. Ha JH, Yoo HJ, Cho IH, Chin B, Shin D, Kim JH. Psychiatric comorbidity assessed in Korean children and adolescents who screen positive for Internet addiction. J Clin Psychiatry 2006;67:821-826.

51. Lee JY, Park EJ, Kwon M, Choi JH, Jeong JE, Choi JS, et al. The difference in comorbidities and behavioral aspects between internet abuse and internet dependence in Korean male adolescents. Psychiatry Investig 2014;11:387-393.

52. Park MH, Park EJ, Choi J, Chai S, Lee JH, Lee C, et al. Preliminary study of Internet addiction and cognitive function in adolescents based on IQ tests. Psychiatry Res 2011;190:275-281. 